\title{
Visão Baseada em Recursos (RBV) e Desempenho de Operadora de Saúde (2006/out 2018)
}

Tania Kadima Magalhães Ferreira; Maria Amélia Matos Nicolau de Lima; Adriane de Oliveira Sales

Introdução: Desempenho organizacional, critério importante, variável dependente de gestão. Teoria RBV prevê vantagem competitiva por recursos internos (capital físico; humano; organizacional), no sentido de serem valiosos, raros, inimitáveis, insubstituíveis. Competência de gestão (ativos tangíveis/intangíveis (financeiros, gestão, processos, rotinas, conhecimentos).

Objetivos: Conforme Diagrama de Influência e de risco verificar se recursos internos foram fatores críticos de sucesso à sustentabilidade de autogestão, pequeno porte, conforme RBV (Influência e Risco) , na monitoração/tratamento dos riscos identificados (atuarial, operacional, gestão, humano). Comparar desempenho organizacional com RBV e competência da gestão.

\section{Metodologia:}

Pesquisa sistema de gestão de operadora; publicações ANS (anuário, índices desempenho), IESS; ABRAPP, tendo por base Estatística, Software Minitab, p-value $<=0,05$.
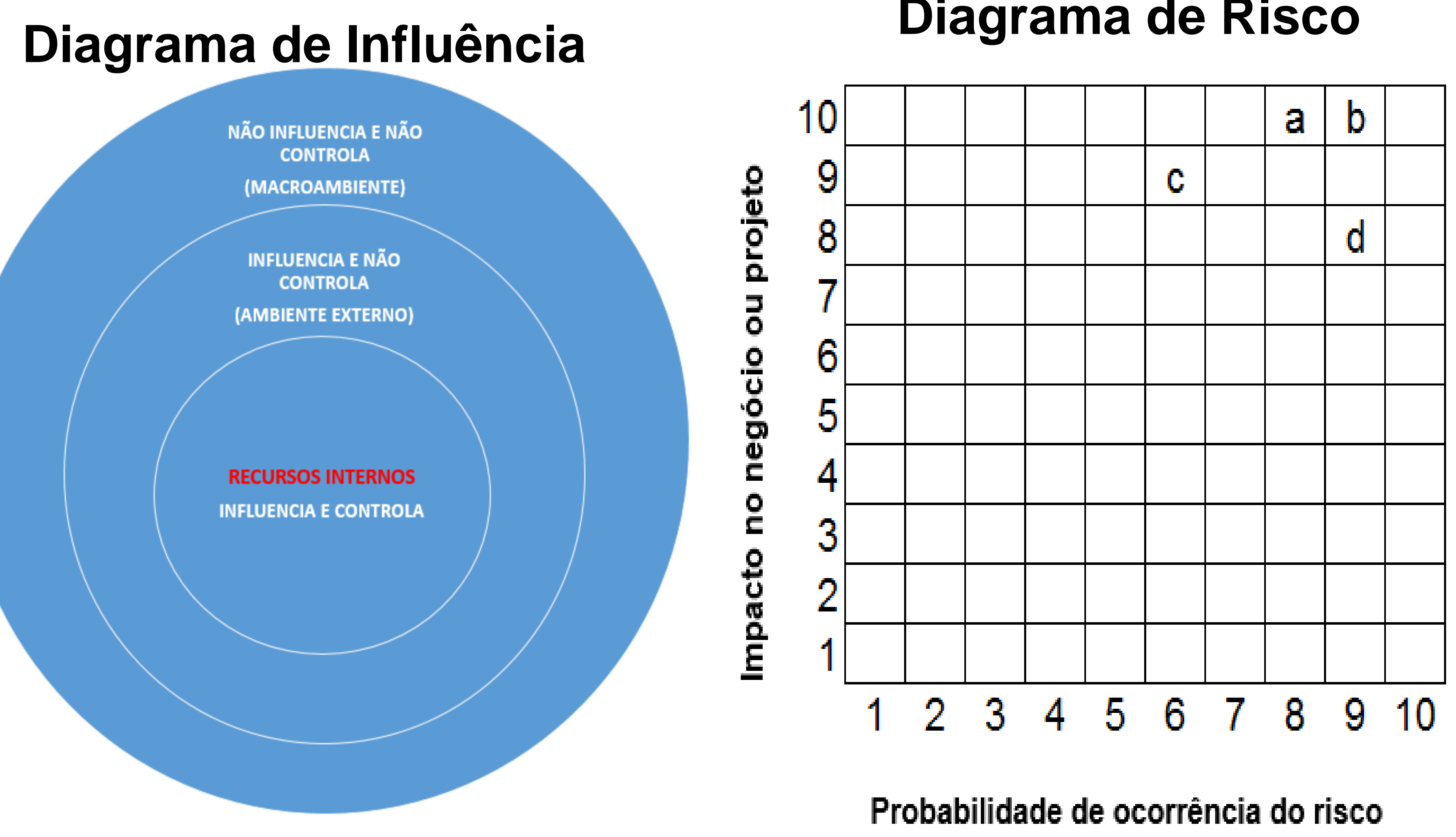

\begin{tabular}{|c|c|c|c|}
\hline Risco & Fator & Pessoa Responsável & Açăo \\
\hline a-Gestä́o & 80 & Atra Administrativia / Diretora Execuliva & Focos stakenodders \\
\hline b- Humano & 90 & Atta Administrativia / Diretora Exectiva & Capacitacăaloceconhecimentio \\
\hline c-Aturaial & 54 & $\begin{array}{l}\text { Eniermeira Coordenadora / Gerente de Qualidadede Assisitente } \\
\text { Social) }\end{array}$ & 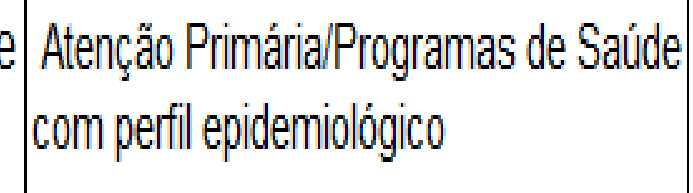 \\
\hline d-Operacional & 72 & 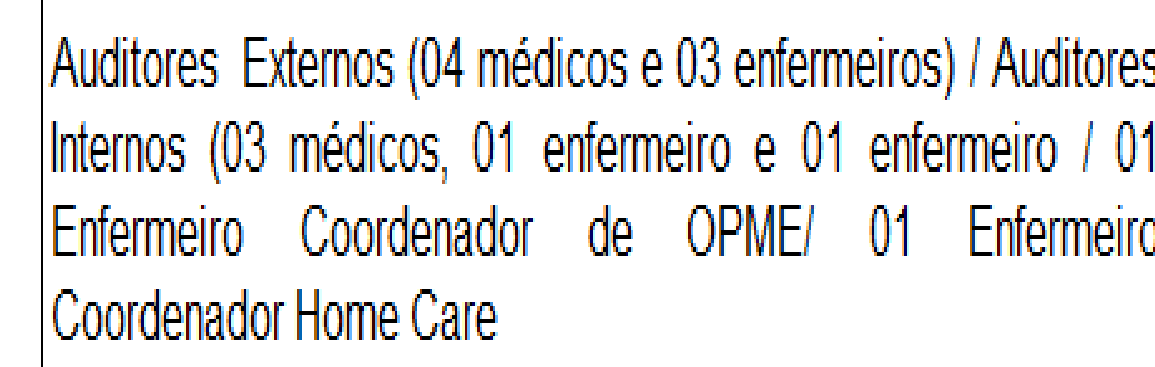 & 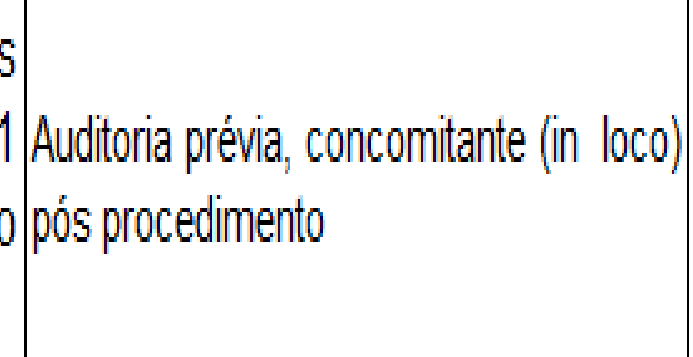 \\
\hline
\end{tabular}

Resultados dos riscos:

a - gestão: equilíbrio financeiro (2009/2018): sinistralidade: $96 \%$ X 85,59\%;

1 - evolução da sinistralidade

\section{SINISTRALIDADE MÚTUA DOS MAGISTRADOS}

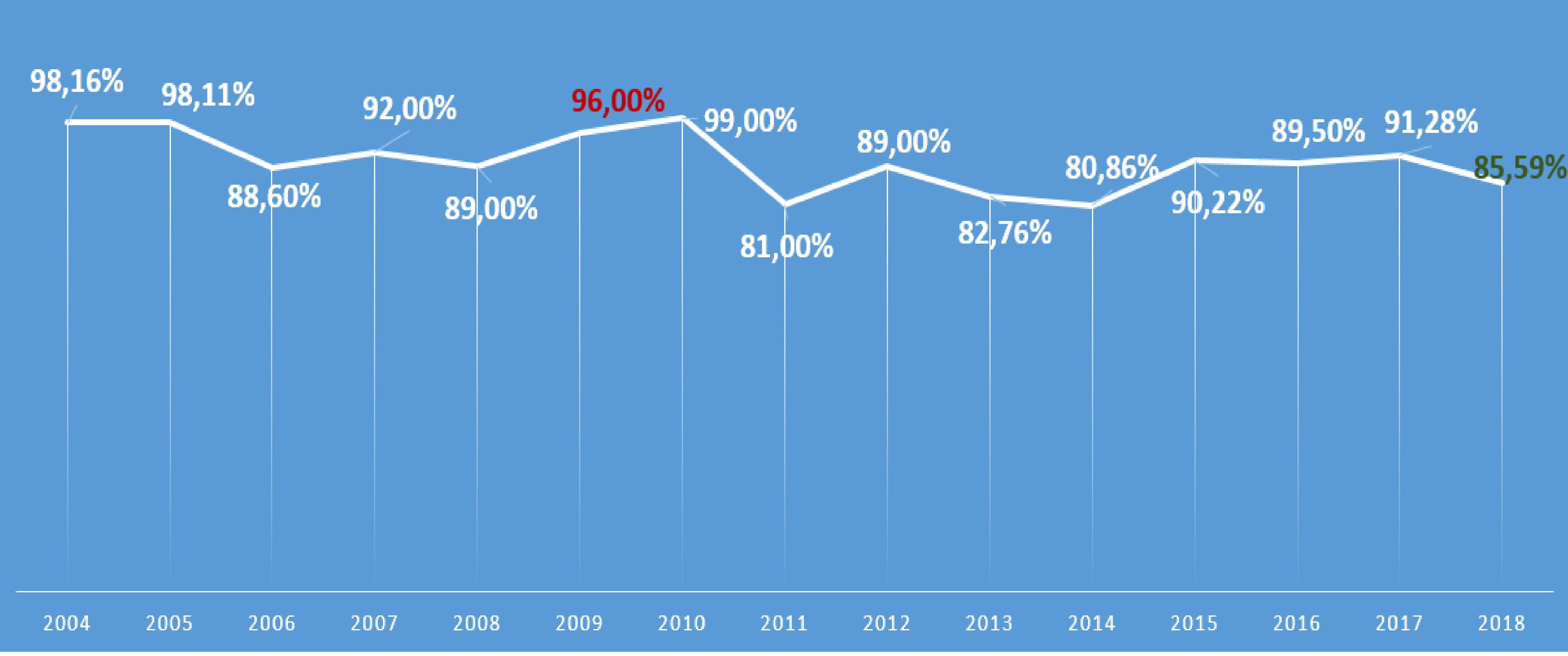

2- assistência: Índice de Desempenho em Saúde Suplementar ANS 2017 (2016)=0,9935;

b- humano: troca por equipe de excelência em 2006 (5 gestores, 57 colaboradores (nível superior); 18 (nível médio);
$\mathrm{HCROI}=$ Receita bruta $-($ Despesas - Ordenados e Benefícios $) /$ Ordenados e Benefícios

\begin{tabular}{lllllllllllll}
2006 & 2007 & 2008 & 2009 & 2010 & 2011 & 2012 & 2013 & 2014 & 2015 & 2016 & 2017 & 2018 \\
\hline 0,81 & 0,53 & 1,41 & 0,43 & 1,21 & 1,88 & 0,56 & 1,22 & 1,69 & 0,05 & 1,17 & 1,00 & 2,18 \\
\hline
\end{tabular}

c- atuariais: (longevidade; doenças crônicas (perfil epidemiológico), minimizadas pela atenção primária ampliada (programas de saúde: controle hipertensão, diabetes, excesso de peso. Fidelização aos programas com diminuição das internações dos participantes dos Programas de Saúde

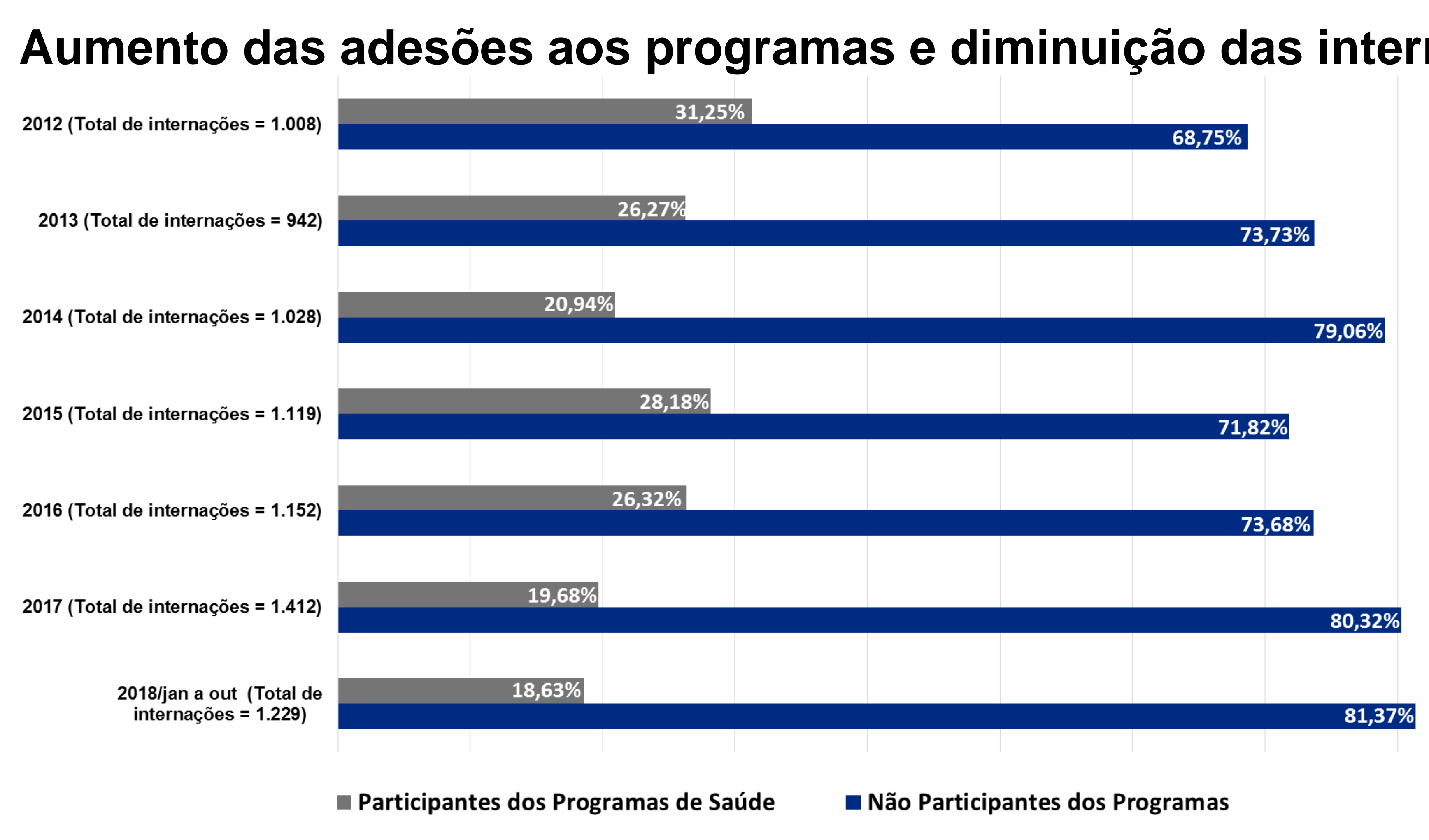

d- operacionais 2006 / 2018:

1- Contas hospitalares: percentual utilização/internações: 2006 $(38,37 \%)$ X $2018(46,02 \%)$, e IESS prevê $2018=61 \%\left(^{*}\right)$.

Percentual de utilização das receitas com internações

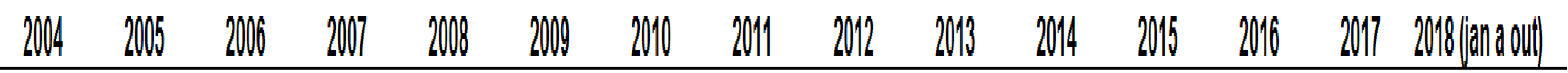

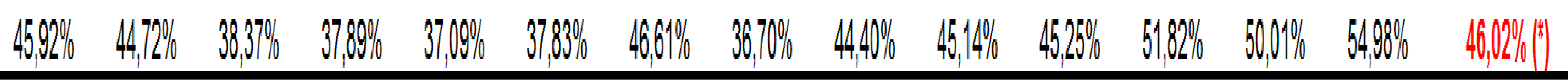

2- redução custo médio/ beneficiário (R\$): OPME's, 11.911,50 X 9.951,96; Home Care, 119.568,94 X 93.178,63.

\section{Custo médio por beneficiário (OPME e Home Care)}

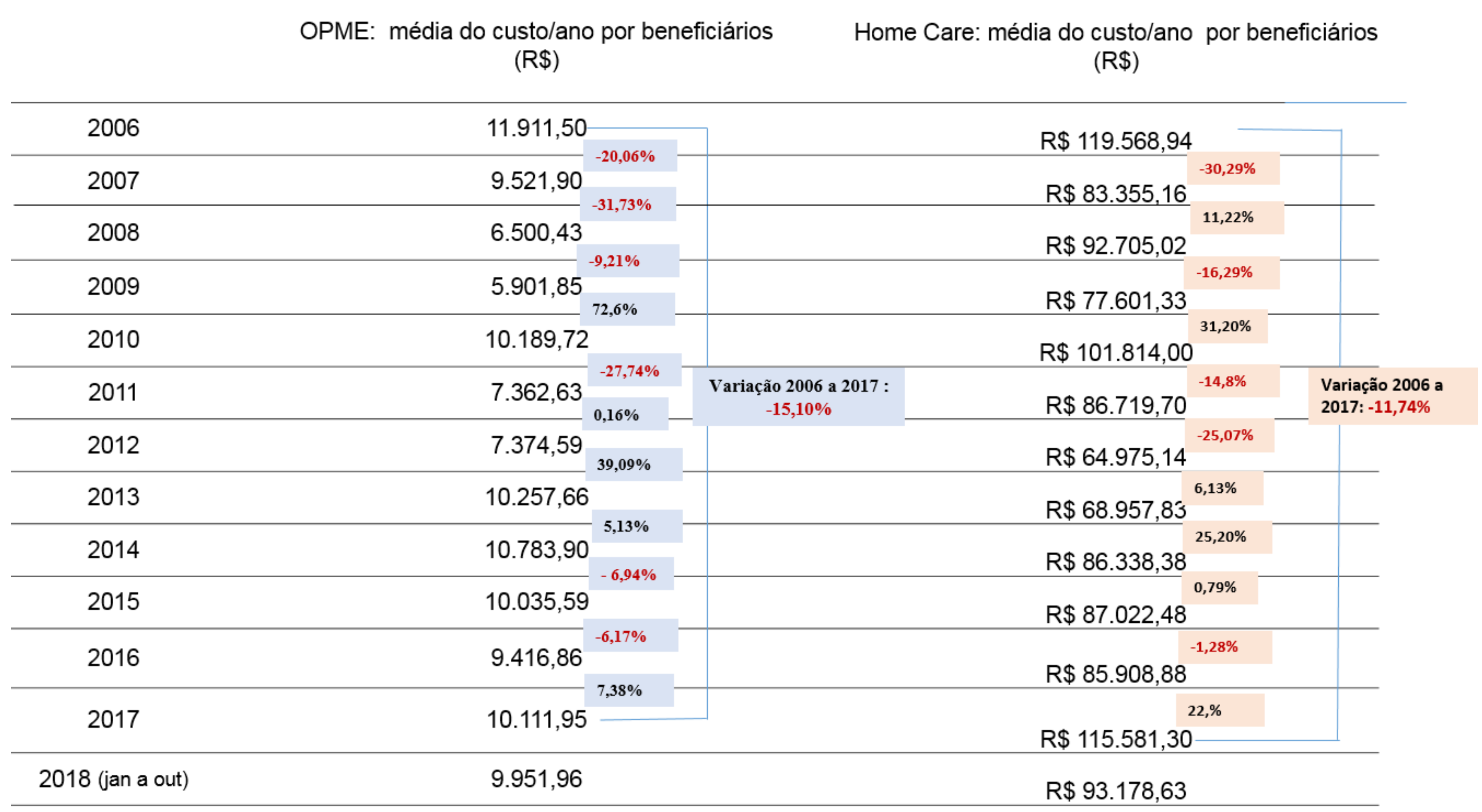

\section{Conclusão:}

Conclui-se pela associação entre vantagem competitiva sustentada e recursos internos (RBV), responsáveis pela alta performance e heterogeneidade duradoura (gestão profissionalizada), tornando a organização singular nos últimos 10 anos (moldes de grandes corporações nacionais e internacionais). Criar valor ao cliente e à empresa, e mantê-los, fez toda diferença, garantia de qualidade e accountability. Possibilidade de RBV orientar demais operadoras de autogestão com fundamento na operadora em estudo, e ratificando pesquisas anteriores sobre RBV.

Referências: Barney, J. 1991. Firm Resources and Sustained Competitive Advantage. 